\title{
Изменения перикисного окисления липидов при бронхиальной обструкции
}

ГОУ ВПО КемГМА Минздравсоцразвития РФ, городская клиническая больница №3, Кемерово

\section{E.A.Vostrikova, O.V.Kuznetsova, I.T.Vetlugaeva, A.V.Tikhonova, G.V.Vavin, P.S.Razumov, A.S.Razumov, A.K.Strelis Changes of peroxidation in bronchial obstruction}

\begin{abstract}
Summary
Chronic obstructive pulmonary disease (COPD) is an environmental disease. Its pathophysiologic basis is chronic inflammation in the lungs provided by the imbalance of pro- and antioxidative systems due to environmental hazards. The purpose of this study was to investigate general patterns of lipid peroxidation changes under the bronchial obstruction. We investigated 252 patients (201 males and 51 females) aged 20 tol 70 years. The clinical and functional features of bronchial obstruction were associated with increase in the lipid peroxidation products level, lowering of the superoxide dismutase activity and growth of the chemoluminescence intensity. The patients with bronchial obstruction had the most severe disorders of the lipid peroxidation which were growth of the dien complexes levels and reduction in the blood antioxidative potential.
\end{abstract}

\section{Резюме}

Хроническая обструктивная болезнь легких (ХОБЛ) - это экологически детерминированное заболевание, патофизиологической основой которого является хронический воспалительный процесс в легких, когда в ответ на действие повреждающих факторов внешней среды нарушается баланс между активностью про- и антиоксидантных систем организма. Цель работы - выявить общие закономерности изменений липопероксидационного статуса при формировании бронхообструктивной патологии. Обследовано 252 человека (201 мужчина и 51 женщина) в возрасте от 20 до 70 лет. Установлено, что клинико-инструментальные признаки бронхиальной обструкции сопряжены с увеличением содержания продуктов липопероксидации, снижением активности супероксиддисмутазы и увеличением интенсивности хемилюминесценции. Пациенты с бронхообструктивными заболеваниями имеют выраженные нарушения липопероксидационного статуса, характеризующиеся увеличением содержания диеновых конъюгатов и снижением антиоксидантного потенциала крови.

Хроническая обструктивная болезнь легких (ХОБЛ) является одной из ведущих причин смертности в промышленно развитых странах, особенно среди малоимущих слоев населения и лиц, занятых тяжелым физическим трудом в условиях холодного климата [1]. По расчетным данным с использованием результатов эпидемиологических исследований, в России ХОБЛ страдают более 11 млн человек [2]. Особую актуальность рассматриваемая проблема приобретает в связи с тем, что благодаря достижениям медицины, смертность от многих заболеваний в последнее время неуклонно снижается. Вместе с тем за период с 1960 по 1996 гг. смертность от ХОБЛ возросла в 3,3 раза у мужчин и в 15 раз у женщин $[3,4]$.

ХОБЛ - заболевание, возникновение и развитие которого детерминируется неблагоприятным воздействием природных и антропогенных факторов окружающей и производственной среды [5]. Согласно современной концепции ХОБЛ, патофизиологической основой прогрессирующей обструкции дыхательных путей является хронический воспалительный процесс в легких, когда в ответ на действие повреждающих факторов внешней среды нарушается баланс между активностью про- и антиоксидантных систем или между активностью протеолитических и антипротеолитических систем $[1,6,7]$. Принимая во внимание то, что уменьшение антипротеолитического потенциала в большинстве случаев обусловлено генетически детерминированной недостаточностью $\alpha_{1}$-антитрипсина, возможности профилактического и терапевтического воздействия на этот фактор в настоящее время весьма ограничены. Представляется целесообразным оценить изменения липопероксидационного (ЛПО) статуса при формировании бронхообструктивной патологии.

Внешние факторы риска развития ХОБЛ, такие как сигаретный дым, ксенобиотики являются мощными инициаторами генерации активных форм кислорода (АФК), оказывающих повреждающее действие на основные структуры легких. Обилие в ткани легких липидных мембран, содержащих большое количество полиеновых жирных кислот, делает их наиболее вероятными мишенями свободнорадикальных процессов. Перекисное окисление липидов (ПОЛ) биологических мембран приводит к нарушению их структурной целостности, ферментативной активности, рецепторной функции, ионного транспорта и т. д. [8].

Система защиты организма от АФК представлена антиоксидантными ферментами - супероксиддисмутазой (СОД), каталазой, различными пероксидазамим и низкомолекулярными соединениями, взаи- 
модействующими с комплексонами ионов металлов переменной валентности и со свободными радикалами с образованием малоактивных продуктов [9]. В норме существует баланс между активностью прои антиоксидантных систем. При нарушении этого баланса под действием ксенобиотиков происходит неконтролируемая активация липопероксидации и образование продуктов ПОЛ, оказывающих при больших концентрациях цитотоксическое действие [10]. В результате возникает ситуация, которая в определенных условиях неизбежно приводит к реализации патогенетических факторов развития ХОБЛ.

Цель исследования - выявление общих закономерностей изменений липопероксидационного статуса при формировании бронхообструктивной патологии.

\section{Материалы и методы}

Обследовано 252 человека (201 мужчина и 51 женщина) в возрасте от 20 до 70 лет, проживающих в г. Кемерово. Средний возраст обследованных $41,1 \pm 0,43$ г.

Исследование проходило в 3 этапа. На первом этапе проводился одномоментный скрининг, включающий опрос с выявлением респираторных жалоб, физикальное обследование, пикфлоуметрию (MiniWrigt AIR Zone), скрининговую спирометрию (Micro DL Micro Medical). Бронхиальная проходимость оценивалась по показателям объема форсированного выдоха за 1-ю с $\left(\mathrm{OФ}_{1}\right)$, пиковой скорости выдоха (ПСВ), форсированной жизненной емкости легких (ФЖЕЛ). За бронхиальную обструкцию принимались показатели ОФВ 1 и ПСВ $<80 \%$ от должных величин, ОФВ 1 ФЖЕЛ $<70 \%$.

На втором этапе для верификации диагноза лицам с подозрением на ХОБЛ проводилось дообследование: осмотр пульмонолога, бронходилатационный тест (БДТ) с использованием стационарного компьютерного спирографа Master Screen Pneumo ("Erich Jaeger", Германия).

На третьем этапе был исследован ЛПО статус определяли супероксиддисмутазную активность плазмы крови, содержание в плазме продуктов ПОЛ, реагирующих с тиобарбитуровой кислотой (ТБК-ап), диеновых (ДК) и триеновых конъюгатов (ТК). Супе- роксиддисмутазную активность определяли по степени блокирования восстановления нитросинего тетразолия, содержание ТБК-ап - по оптической плотности, измеренной на спектрофотометре СФ-46 в бутанольном экстракте при длине волны 535 нм, содержание ДК и ТК - спектрофотометрически в гептановом экстракте при 232 и 278 нм. Определяли показатели хемилюминесценции (ХЛ): интенсивность (max ХЛ) - амплитуда максимальной вспышки, соответствующая концентрации гидроперекисей, и период полузатухания, определяемый как время (с), в течение которого интенсивность ХЛ достигает полуамплитуды вспышки. Длительность периода полузатухания обратно пропорциональна содержанию антиоксидантов в исследуемой пробе.

Полученные данные были обработаны с помощью t-критерия Стьюдента после проверки на нормальность распределения в пакете программ Microsoft Excel. Сравнение частот проводилось с использованием критерия Пирсона $\chi^{2}$. Используемые статистические термины: $M$ - выборочное среднее, $m$ - ошибка среднего, $p$ - достигнутый уровень значимости. Критический уровень значимости при проверке статистических гипотез в данном исследовании принимался равным 0,05.

\section{Результаты и обсуждение}

Нами была выявлена связь между изменениями окислительного метаболизма и клиническими признаками бронхолегочной патологии (табл. 1).

У пациентов, предъявляющих жалобы на кашель, были подтверждены значительные изменения ЛПО статуса: повышено содержание ДК и ТК, снижена активность СОД, увеличена интенсивность ХЛ. Изменения показателей ЛПО статуса оказались более выраженными у пациентов, предъявляющих жалобы на кашель, по сравнению с больными, основной жалобой который была одышка. При этом Т-ХЛ и содержание ТБК-ап достоверно не изменялись.

Однако такие клинические симптомы, как кашель и одышка, лишь косвенно отражают состояние бронхиальной проходимости. Более точной характеристикой являются спирометрические показатели, оценка которых подтвердила, что пациенты с инструментально подтвержденной бронхиальной

Таблица 1

Показатели ЛПО статуса в зависимости от респираторных жсалоб ( $\mathrm{M} \pm \mathrm{m})$

\begin{tabular}{|c|c|c|c|c|c|c|c|}
\hline \multirow[b]{2}{*}{ Симптомы } & \multirow[b]{2}{*}{$n$} & \multicolumn{6}{|c|}{ Показатели липопероксидации } \\
\hline & & $\begin{array}{c}\text { ДК, } \\
\text { ед. оп. пл. }\end{array}$ & $\begin{array}{c}\text { ТК } \\
\text { ед. оп. пл. }\end{array}$ & $\begin{array}{l}\text { ТБК-ап, } \\
\text { нмоль / мл }\end{array}$ & $\begin{array}{c}\text { сод, } \\
\text { усл. ед. }\end{array}$ & $\begin{array}{l}\text { max ХЛ, } \\
\text { усл. ед. }\end{array}$ & $\begin{array}{c}\text { Т-ХЛ, } \\
\text { c }\end{array}$ \\
\hline Кашель & 103 & $0,42 \pm 0,008$ & $0,042 \pm 0,0009$ & $6,40 \pm 0,391$ & $0,50 \pm 0,011$ & $1,29 \pm 0,051$ & $5,83 \pm 0,265$ \\
\hline Нет кашля & 149 & $0,40 \pm 0,006$ & $0,040 \pm 0,0007$ & $5,90 \pm 0,254$ & $0,53 \pm 0,009$ & $1,13 \pm 0,054$ & $5,78 \pm 0,150$ \\
\hline$p$ & & 0,014 & 0,045 & $>0,05$ & 0,005 & 0,008 & $>0,05$ \\
\hline Одышка & 42 & $0,41 \pm 0,010$ & $0,04 \pm 0,001$ & $6,90 \pm 0,71$ & $0,48 \pm 0,017$ & $1,34 \pm 0,066$ & $5,62 \pm 0,445$ \\
\hline Нет одышки & 210 & $0,41 \pm 0,005$ & $0,04 \pm 0,001$ & $5,90 \pm 0,22$ & $0,52 \pm 0,007$ & $1,19 \pm 0,035$ & $5,82 \pm 0,140$ \\
\hline$p$ & & $>0,05$ & $>0,05$ & $>0,05$ & 0,009 & 0,028 & $>0,05$ \\
\hline
\end{tabular}


Таблица 2

Показатели ЛПО статуса в зависимости от бронхиальной проходимости (M \pm m)

\begin{tabular}{|c|c|c|c|c|c|c|c|}
\hline Показатель & $n$ & дК & TK & ТБК-ап & сод & $\max X Л$ & Т-ХЛ \\
\hline $50 \%>0 \Phi B_{1}$ & 3 & $0,500 \pm 0,067$ & $0,0483 \pm 0,0073$ & $6,48 \pm 2,630$ & $0,425 \pm 0,058$ & $1,31 \pm 0,053$ & $6,74 \pm 0,907$ \\
\hline $80 \%>0 \Phi B_{1}>50 \%$ & 26 & $0,439 \pm 0,017$ & $0,0466 \pm 0,0019$ & $6,07 \pm 0,402$ & $0,494 \pm 0,024$ & $1,08 \pm 0,126$ & $6,23 \pm 0,298$ \\
\hline $0 \Phi B_{1}>80 \%$ & 223 & $0,407 \pm 0,005$ & $0,0405 \pm 0,0006$ & $6,11 \pm 0,240$ & $0,521 \pm 0,007$ & $1,22 \pm 0,034$ & $5,57 \pm 0,143$ \\
\hline$p$ & & ${ }_{2-3} 0,037$ & ${ }_{2-3} 0,002$ & $>0,05$ & $>0,05$ & $>0,05$ & ${ }_{2-3} 0,047$ \\
\hline $50 \%>\pi \mathrm{CB}<50 \%$ & 3 & $0,409 \pm 0,024$ & $0,0369 \pm 0,0041$ & $9,17 \pm 0,060$ & $0,443 \pm 0,061$ & $0,88 \pm 0,380$ & $6,80 \pm 0,047$ \\
\hline $80 \%>n C B>50 \%$ & 14 & $0,502 \pm 0,040$ & $0,0520 \pm 0,0032$ & $6,15 \pm 0,627$ & $0,438 \pm 0,045$ & $1,24 \pm 0,104$ & $5,87 \pm 0,411$ \\
\hline ПСВ $>80 \%$ & 235 & $0,406 \pm 0,004$ & $0,0406 \pm 0,0005$ & $6,09 \pm 0,229$ & $0,523 \pm 0,006$ & $1,21 \pm 0,033$ & $5,77 \pm 0,141$ \\
\hline \multirow[t]{2}{*}{$p$} & & $4-50,034$ & $4-50,017$ & ${ }_{4-5}<0,001$ & 5-6 0,044 & $>0,05$ & $4-50,034$ \\
\hline & & ${ }_{5-6} 0,016$ & ${ }_{5-6} 0,002$ & ${ }_{4-6}<0,001$ & & & ${ }_{4-6}<0,001$ \\
\hline
\end{tabular}

обструкцией $\left(\mathrm{OФВ}_{1}\right.$ и ПСВ $\left.<80 \%\right)$ имеют существенные изменения показателей ЛПО статуса (табл. 2).

Свободнорадикальные процессы при бронхиальной обструкции характеризуются активацией липопероксидации (увеличение содержания ДК и ТК), истощением СОД-активности, снижением антиоксидантного потенциала (по Т-ХЛ). Содержание ТБК-ап повышается лишь при выраженном снижении бронхиальной проходимости. Не было выявлено различий только в отношении интенсивности ХЛ, что, по-видимому, связано с разнонаправленной динамикой этого показателя по мере прогрессирования бронхообструктивной патологии.

Для уточнения механизма связи метаболических и респираторных изменений был проведен анализ динамики ОФВ и ПСВ в зависимости от показателей ЛПО статуса (рис. 1). Установлено снижение ОФВ 1 и ПСВ при увеличении ДК $(r=-0,64$ и $-0,48$ соответственно) и ТК ( $r=-0,65$ и $-0,31)$. Связь между спирометрическими показателями и ТБК-ап выражена несколько слабее: $r=-0,20$ для ОФВ 1 и $r=-0,33$ для ПСВ. Снижение активности СОД сопряжено с ухудшением бронхиальной проходимости $(r=0,55$ и 0,42 для ОФВ 1 и ПСВ).

По данным хемилюминесцентного анализа, бронхиальная обструкция сопровождается увеличением интенсивности ХЛ $(r=-0,36$ и $-0,20$ для ОФВ и ПСВ) и с увеличением Т-ХЛ $(r=-0,66$ и $-0,19$ для $\mathrm{OФB}_{1}$ и ПСВ), величина которого обратно пропорциональна антиоксидантному потенциалу крови.

Скрининговое определение респираторной функции, включающая анкетирование и спирометрию, как и любые диагностические тесты, допускает возможность ложноположительных или ложноотрицательных результатов. Для оценки истинных показателей распространенности ХОБЛ было проведено дообследование лиц с подозрением на бронхообструктивную патологию (второй этап). Верификация диагноза ХОБЛ основывалась на анамнестических данных, оценке симптоматики и объективного статуca, результатах измерения ограничения воздушного потока [1]. Приоритетным критерием диагностики было снижение ОФВ 1 ФЖЕЛ $<70$ \%. Учитывали отсутствие улучшения или нормализации показателей бронхиальной проходимости после БДТ - постброн-
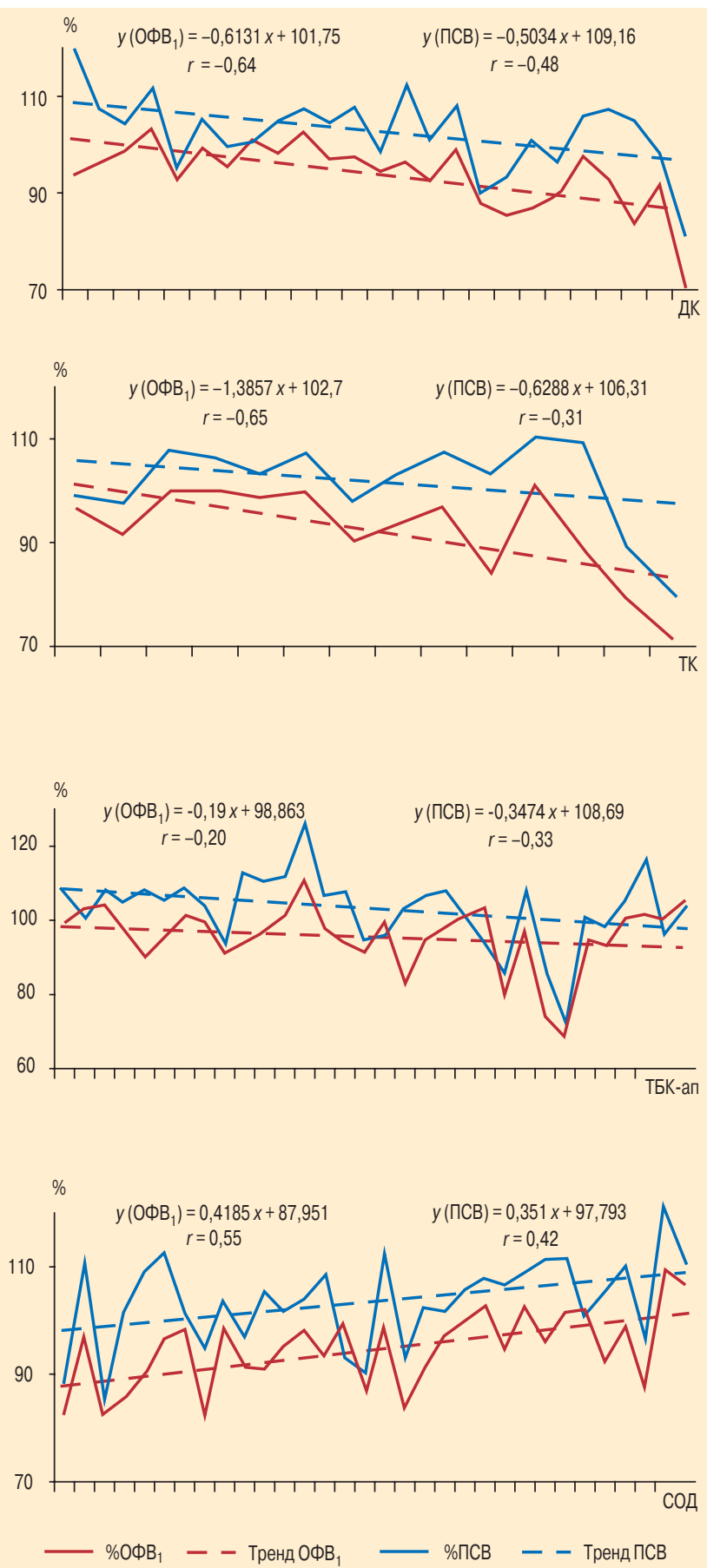

Рис.1. Зависимость ОФВ и ПСВ от показателей ЛПО статуса 
ходилатационное снижение ОФВ 1 и / или ПСВ $<80 \%$ от должных величин. У пациентов с жалобами на постоянный кашель и / или продукцию мокроты на протяжении двух и более лет, при наличии длительно существующих факторов риска и нормальных спирометрических показателях, диагностировали ХОБЛ 0 -й ст., т. е. по принятой отечественной терминологии - хронический необструктивный бронхит.

Исследование параметров ЛПО статуса у пациентов с бронхообструктивной патологией (рис. 2) подтвердило, что при ХОБЛ и ХБ увеличено содержание ДК и ТК, снижена активность СОД. У больных ХОБЛ было выявлено снижение концентрации ТБК-ап, интенсивности ХЛ и антиоксидантного потенциала крови (по Т-ХЛ). Повышение интенсивности ХЛ было обнаружено у пациентов с ХБ и БА.

\section{Выводы}

1. Респираторные жалобы и инструментальные признаки бронхиальной обструкции сопряжены с увеличением содержания продуктов липопероксидации, снижением активности СОД и увеличением интенсивности ХЛ.

2. Развитие и прогрессирование бронхообструктивной патологии сопряжены с дисбалансом про- и антиоксидантных процессов.

3. Нарушения ЛПО статуса наиболее выражены у пациентов с бронхообструктивными заболеваниями и характеризуются увеличением содержания продуктов липопероксидации и снижением активности СОД.

\section{Литература}

1. Global Initiative for Chronic Obstructive Lung Disease (GOLD). National Heart, Lung, and Blood Institute. Publication № 2701, April 2001.

2. Хроническая обструктивная болезнь легких: Практическое руководство для врачей. М; 2004.

3. Чучалин А.Г. Белая книга Пульмонология. Россия 2003. M; 2003.

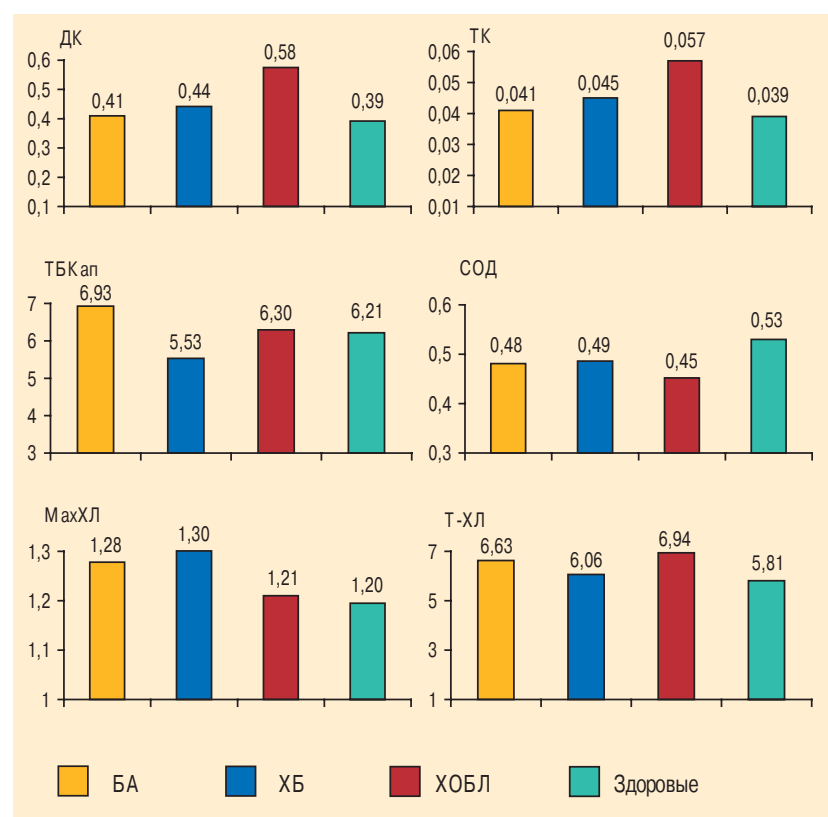

Рис. 2. Среднее значение показателей ЛПО статуса у пациентов с БА, ХБ, ХОБЛ и у здоровых

4. Чучалин А.Г. Хронические обструктивные болезни легких. М.: БИНОМ; 2000.

5. Шмелев Е.И. ХОБЛ: ключевые проблемы. Атмосфера. Пульмонол. и аллергол. 2003; 2: 5-9.

6. Соодаева С.К. Оксидантные и антиоксидантные системы легких при хронических обструктивных заболеваниях. В кн.: Хронические обструктивные болезни легких. М.: БИНОМ; 2000. 92-111.

7. Соодаева С.К. Роль свободнорадикального окисления в патогенезе ХОБЛ. Атмосфера, 2002; 1: 24-25.

8. Пол У. Иммунология. М.; 1989; т. 3: 22-27.

9. Владимиров Ю.А., Потапенко А.Я. Физико-химические основы фотобиологических процессов. М.: Высшая школа; 1989. 170-179.

10. Гольденберг Ю.М., Кокосов А.Н., Мищенко В.П. и др. Свободно-радикальное окисление в генезе болезней органов дыхания. Пульмонология 1991; 4: 50-55.

Поступила 30.08 .05 (๑) Коллектив авторов, 2006 удк 616.233-007.27107:616-008.939.15-074 